\title{
Using Genetic Panels to Predict Tenderness in Beef Cattle
}

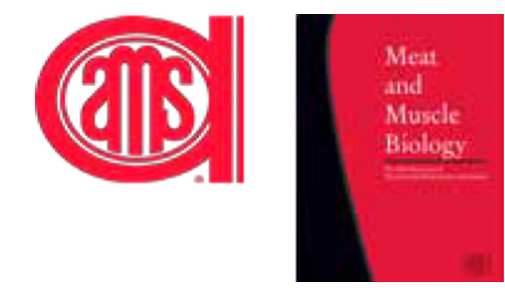

\author{
Tanya M. Weber, Michael J. Colle*, Gordon K. Murdoch, Brianna J. Buseman, \\ Jessica M. Lancaster, Jessie B. Van Buren, James A. Nasados, and Phillip D. Bass \\ Department of Animal and Veterinary Science, University of Idaho, Moscow, Idaho 83844, USA \\ *Corresponding author. Email: mjcolle@uidaho.edu (Michael J. Colle)
}

\begin{abstract}
Genetic panel use as a selection tool has grown in popularity in the beef industry. The objective of the study was to determine whether beef cattle genetically selected for tenderness generated a tender product. Igenity $($ IT) panel results were provided by a cattle producer for 52 steers, which were harvested at a commercial harvest facility. Boneless strip loins (Institutional Meat Purchase Specifications \#180; United States Department of Agriculture [USDA] Choice, $n=32$; USDA Prime $n=20$ ) were collected from the left side of each carcass and transported to the University of Idaho Meat Science Laboratory. Four steaks were cut from each subprimal and assigned to aging periods of 7, 14, and $21 \mathrm{~d}$ for Warner-Bratzler Shear Force (WBSF) analysis or $21 \mathrm{~d}$ for consumer sensory analysis. Carcasses were assigned to tenderness groups based on their IT tenderness indexes (Low IT, 3-6, $n=30$; High IT, 7-10, $n=22$ ). Data were analyzed using the mixed model procedure of SAS version 9.4 (SAS Institute Inc., Cary, NC). An interaction was observed between tenderness group and USDA quality grade $(P=0.015)$ when analyzing WBSF. All of the cattle had less than $4.14 \mathrm{~kg}$ of WBSF; however, USDA Prime steers that were in the High IT tenderness group produced more tender steaks than High IT USDA Choice, Low IT USDA Prime, and Low IT USDA Choice steers. Consumers were not able to detect tenderness differences between IT tenderness groups $(P=0.11)$ or USDA quality grades $(P=0.11)$, but they found USDA Prime steaks to be more acceptable $(P=0.01)$, juicier $(P=0.01)$, and more flavorful $(P=0.02)$ than USDA Choice steaks. In conclusion, regardless of tenderness group, USDA Prime steaks were preferred by consumers over USDA Choice steaks in terms of flavor, juiciness, and acceptability.
\end{abstract}

Key words: beef, genetic panel, tenderness, Igenity $\mathbb{R}$

Meat and Muscle Biology 4(1): 17, 1-8 (2020) doi:10.22175/mmb.9549

Submitted 22 January $2020 \quad$ Accepted 2 May 2020

\section{Introduction}

Genetic panel use as an animal selection tool is growing in popularity in the United States beef industry due to its complementary function alongside the sole use of somewhat more traditional expected progeny differences (Pollak et al., 2012). These tests continue to improve in availability and affordability as the field of genomics is further explored (Hocquette et al., 2007; Picard et al., 2015; Van Eenennaam, 2016).

Improving carcass quality is a goal of many beef producers because of consumer reports of the importance of beef tenderness (Schroeder et al., 2013). Picard et al. (2014) identified variability in tenderness to be a big issue facing the beef industry. Historically, producers have been able to make subjective predictions based on visual evaluation, but that information is highly variable depending on the person doing the evaluation (Hedrick, 1983). Even the most experienced visual evaluator is not able to predict important carcass quality traits such as tenderness, which Koohmaraie et al. (1995), Miller et al. (2001), and Koohmaraie and Geesink (2006) showed is the most important quality trait that influences a consumer's willingness to purchase that product again. 
The Igenity® (IT) tenderness index evaluates single nucleotide polymorphisms for $\mu$-calpain, a proteolytic enzyme responsible for postmortem muscle breakdown (Geesink et al., 2006), and calpastatin, a potent inhibitor of $\mu$-calpain (Goll et al., 2003; Kemp et al., 2009). Postmortem proteolysis-and therefore tenderization - is largely affected by concentrations and activities of calpain and calpastatin within the muscle (Koohmaraie, 1992, 1994; Warner et al., 2010). In addition to calpain and calpastatin activity, tenderness is affected by many environmental factors, including the age of the animal, cooking methods, use of beta-agonists, and degree of doneness (Huff and Parrish Jr., 1993; Hope-Jones and Strydom, 2010; Warner et al., 2010). If it is possible to use selection tools that can give insight into an animal's genotype for tenderness, it would be possible to predict what quality of carcasses its progeny could produce. Additionally, producers could provide an environment (i.e., more aggressive beta-agonist strategy), that will maximize growth and capitalize on that genetic ability to produce a tender product if they were aware of the animal's potential. These tools would be well suited for use as a selection tool for replacement heifers and for seedstock producers because these producers would be able to say that their animals have a high chance $\left(h^{2}=0.53 \pm 0.15\right.$ for Warner-Bratzler Shear Force [WBSF] tenderness; Shackelford et al., 1994) of producing progeny that will generate a tender product.

The objective of this study was to evaluate tenderness of cattle that were specifically selected for tenderness.

\section{Materials and Methods}

\section{Human subject participation in consumer panel}

The University of Idaho Institutional Review Board certified this project as exempt.

\section{Product procurement}

IT panel results were provided by a commercial producer for 52 beef steers whose parents were selected for their tenderness index scores. The steers were harvested at a commercial harvest facility in Toppenish, Washington, and allowed to chill for $24 \mathrm{~h}$. Carcasses were fabricated, and boneless strip loins (Institutional Meat Purchase Specifications \#180) were produced, vacuum packaged, and stored under refrigeration at $4^{\circ} \mathrm{C}$. The strip loins were transported under chilled conditions $24 \mathrm{~h}$ post fabrication to Vandal Brand Meats in Moscow, Idaho, where four 2.54-cm-thick steaks were cut from the anterior end of each subprimal and subsequently vacuum packaged. Steaks were randomly assigned by order of removal from the strip loin to one of 3 aging groups $(7,14$, and $21 \mathrm{~d}$ post mortem) to be evaluated for WBSF or aged for $21 \mathrm{~d}$ post mortem to be evaluated by an untrained consumer sensory panel for subjective tenderness, juiciness, flavor, and acceptability. Strip loins were organized into tenderness groups based on their IT tenderness indexes. Carcasses were assigned to High IT $(n=22)$ or Low IT $(n=30)$, with the High IT group including steaks from carcasses that received an IT tenderness index of 7-10 and the Low IT group including steaks that came from carcasses that received an IT tenderness index of 3-6, similar to McEvers et al. (2012).

\section{Carcass characteristics}

Hot carcass weight (HCW) data were measured at the commercial harvest facility. Additionally, ribeye area (REA), 12th rib backfat (BF), and marbling score (MS) were recorded using a camera grading system (E+V Technology GmbH \& Co. KG, Oranienburg, Germany). Carcasses were then assigned US Department of Agriculture (USDA) quality grades (USDA Choice, $n=32$; USDA Prime $n=20$ ) and USDA yield grades by a USDA grader following the camera grading system.

\section{Cooking}

Steaks were thawed for $24 \mathrm{~h}$ at $4^{\circ} \mathrm{C}$ and then weighed prior to cooking. Steaks were then cooked on a clamshell style Cuisinart grill (Cuisinart Griddler Deluxe Model GR-150) that was set to $203^{\circ} \mathrm{C}$ to a target peak internal temperature of $71^{\circ} \mathrm{C}$. Temperatures were monitored using a type $\mathrm{K}$ thermocouple (93230-K EconoTemp, Cooper-Atkins, Middlefield, CT) placed at the geometric center of each steak.

\section{WBSF}

Steaks were cooked as described earlier and removed from the grill at $65^{\circ} \mathrm{C}$. Temperature was monitored until it began to decline, at which time the peak temperature was recorded. The cooked steaks were allowed to cool to room temperature on a tray. Once cooled, steaks were weighed again to determine cook loss. At least 6 cores were cut from each steak 
parallel to the muscle fibers from the steaks, with care taken to avoid connective tissue and excess fat using a Shop Fox W1667 8-1/2" oscillating drill press with a 1.27-cm-diameter coring bit attachment. All cores were sheared using a Warner-Bratzler Meat Shear $(\mathrm{G} \bullet \mathrm{R}$ Manufacturing, Manhattan, KS; BFG 1,000 N) machine, and the peak shear force of each core was recorded. The average of the shear force values for all cores from each respective steak were analyzed to determine the WBSF of each steak.

\section{Consumer sensory panel}

Seventy-two consumer panelists evaluated samples over the course of $1 \mathrm{~d}$ in sensory booths, which were located at the Washington State University Sensory Evaluation Facility. Panelists were in a booth with unfiltered light. Sessions were 30 min long, with 8 panelists per session. Panelists were given a questionnaire that asked them to rank each sample based on their observation of tenderness, flavor, juiciness, and overall acceptability on a scale of $1-9$, with 1 being "Dislike Extremely" and 9 being "Like Extremely." Each panelist was randomly assigned a steak sampling order using the Compusense program (Compusense Inc., Guelph, Canada; N1G 4T2), and they were given one sample at a time to evaluate with $30 \mathrm{~s}$ of rest time between each sample. Steaks were cooked as described earlier and kept under a warming lamp for no longer than 15 min after cooking. Steaks were randomly assigned to a cooking order based on the 8-panelist sessions so that samples did not sit under the warming heat lamp for an extended period of time. Samples were cut into $1.27 \mathrm{~cm} \times 1.27 \mathrm{~cm}$ cubes. Panelists were given tap water and salt-free soda crackers to cleanse their palette between samples. Each panelist evaluated 3 samples. Each steak was represented in the panel with a minimum of 4 samples. Eight steaks were randomly assigned to be represented 5 times, in order to appropriately serve each panelist 3 samples.

\section{Statistical analysis}

Data were analyzed using the generalized linear mixed model assuming a normal distribution. Within each model, aging treatment, IT tenderness group, USDA quality grade, and the interaction between IT tenderness group and USDA quality grade were fixed effects, and peak cook temperature was included as a covariate. WBSF data were analyzed as repeated measures. Significance was determined at $P<0.05$. For significant fixed effects, means were separated using pair-wise comparisons. All statistical analyses were carried out using SAS version 9.4 (SAS Institute Inc., Cary, NC).

\section{Results}

\section{Carcass characteristics}

Carcass characteristics are summarized in Table 1. No difference in mean HCW $(P=0.22)$ or MS $(P=$ $0.13)$ was observed between High IT and Low IT groups. High IT carcasses had lesser mean BF $(P<$ $0.01)$ and greater mean REA $(P<0.01)$ than Low IT carcasses. USDA Choice carcasses had lesser mean MS $(P<0.01)$, larger mean REA $(P<0.01)$, lesser mean $\mathrm{BF}(P<0.01)$, and lighter mean $\mathrm{HCW}(P<$ 0.01) than USDA Prime carcasses.

Table 1. Carcass summary statistics

\begin{tabular}{|c|c|c|c|c|c|c|c|c|}
\hline & $n$ & $\begin{array}{l}\text { IT Tenderness } \\
\text { Index }\end{array}$ & $\begin{array}{l}\text { IT Tenderness } \\
\text { Index Range }\end{array}$ & $\mathrm{BF}^{1}$ & $\mathrm{HCW}$ & REA $^{1}$ & $\mathrm{USDA} \mathrm{YG}^{2}$ & $\mathrm{MS}^{1_{\dagger}}$ \\
\hline High IT & 22 & 8 & $7-10$ & $0.21 \pm 0.01^{\mathrm{b}}$ & $413 \pm 4$ & $14.5 \pm 0.09^{\mathrm{a}}$ & 2 & $724 \pm 9$ \\
\hline Low IT & 30 & 5 & $3-6$ & $0.24 \pm 0.01^{\mathrm{a}}$ & $407 \pm 4$ & $13.7 \pm 0.05^{b}$ & 2 & $741 \pm 8$ \\
\hline Choice $^{2}$ & 32 & 6 & $3-10$ & $0.20 \pm 0.01^{\mathrm{y}}$ & $418 \pm 3^{x}$ & $14.4 \pm 0.05^{\mathrm{x}}$ & 2 & $648 \pm 7^{y}$ \\
\hline Prime $^{2}$ & 20 & 6 & $3-9$ & $0.24 \pm 0.01^{\mathrm{x}}$ & $402 \pm 4^{y}$ & $13.8 \pm 0.09^{y}$ & 2 & $817 \pm 9^{x}$ \\
\hline \multicolumn{9}{|c|}{ Values for BF (12th rib BF; $\mathrm{cm}), \mathrm{HCW}(\mathrm{kg}), \mathrm{REA}\left(\mathrm{cm}^{2}\right)$, and MS are represented as mean $\pm \mathrm{SEM}$. } \\
\hline \multicolumn{9}{|c|}{${ }^{1}$ Evaluated by commercial harvest facility grading camera. } \\
\hline \multicolumn{9}{|c|}{${ }^{2}$ Assigned by USDA grader at packing plant following grading camera. } \\
\hline \multicolumn{9}{|c|}{${ }^{\dagger}$ MS: 600-699 = "Choice +"; 700-799 = "Prime -"; 800-899= "Prime ${ }^{\circ} . "$} \\
\hline \multicolumn{9}{|c|}{${ }^{\mathrm{a}, \mathrm{b}}$ Within a column, means without a common superscript differ $(P<0.05)$. } \\
\hline \multicolumn{9}{|c|}{ x,y Within a column, means without a common superscript differ $(P<0.05)$. } \\
\hline $\mathrm{BF}=\mathrm{b}$ & ; HC & ot carcass weig & $=$ Igenity $® ; M S$ & ling score; R & ribeye are & $\mathrm{A}=\mathrm{US}$ Dep & tof Agricult & $\mathrm{G}=$ yield \\
\hline
\end{tabular}




\section{Cooking}

The average peak internal temperature for steaks analyzed for WBSF was $73.61^{\circ} \mathrm{C} \pm 0.41^{\circ} \mathrm{C}$. Average cook loss for all steaks was $20.21 \% \pm 0.31 \%$.

\section{WBSF}

Aging period did not significantly impact WBSF $(P=0.33)$. An interaction was observed between tenderness group and USDA quality grade $(P=0.015$; Figure 1). High IT steaks that graded USDA Prime had lesser shear force values than High IT steaks that graded USDA Choice, Low IT steaks that graded USDA Prime, and Low IT steaks that graded USDA Choice.

\section{Consumer sensory panel}

Consumer sensory panel demographics are summarized in Table 2. There were no interactions observed between tenderness group and USDA quality grade when analyzing consumer sensory data $(P=$ 0.39 ). Consumers were not able to detect tenderness differences between IT tenderness groups $(P=0.11$; Table 3). Furthermore, there were no differences between IT tenderness groups in terms of consumer perception of flavor $(P=0.44)$, but there was a tendency for consumers to prefer High IT steaks over Low IT steaks when evaluating juiciness $(P=0.09)$. Furthermore, consumers preferred High IT steaks over

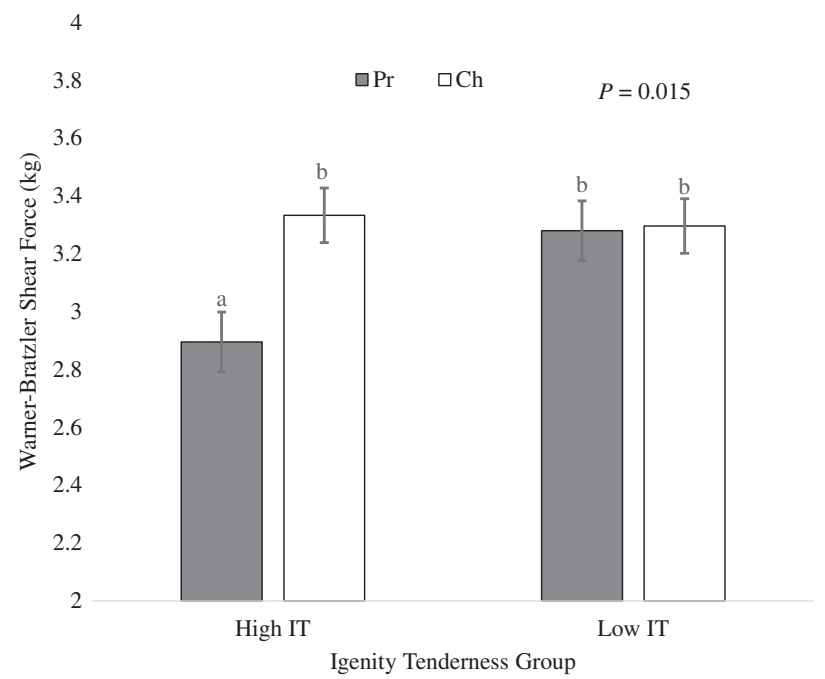

Figure 1. WBSF values for IT tenderness group [Low IT (IT tenderness index scores 3-6) and High IT (IT index scores 7-10)] $\times$ USDA quality grade. The High IT group had 12 USDA Choice carcasses and 10 USDA Prime carcasses, whereas the Low IT group had 20 USDA Choice carcasses and 10 USDA Prime carcasses. Gray bars show USDA Prime carcasses, and white bars show USDA Choice carcasses. IT = Igenity $\mathbb{R}$; USDA = US Department of Agriculture; WBSF $=$ Warner-Bratzler Shear Force.
Table 2. Demographics of consumer panelists $(n=$ 72)

\begin{tabular}{lrr}
\hline \hline Age & $n$ & $\%$ \\
$20-29$ & 30 & 41.6 \\
$30-39$ & 20 & 27.8 \\
$40-49$ & 10 & 13.9 \\
$50+$ & 12 & 16.7 \\
Gender & & \\
Male & 25 & 34.7 \\
Female & 47 & 65.3 \\
Beef meals/wk & & \\
$0-1$ & 7 & 9.7 \\
$2-4$ & 53 & 73.6 \\
5-7 & 12 & 16.7 \\
Most consumed & & \\
Ground & 47 & 65.3 \\
Roast & 5 & 6.9 \\
Steak & 18 & 25.0 \\
Other & 2 & 2.8 \\
\hline
\end{tabular}

Table 3. Effects of IT tenderness score on palatability traits assessed by consumer sensory panel

\begin{tabular}{|c|c|c|c|c|}
\hline \multirow[b]{2}{*}{ Trait } & \multicolumn{2}{|c|}{ IT Tenderness Group } & \multirow[b]{2}{*}{ SEM } & \multirow[b]{2}{*}{$P$ value } \\
\hline & Low $(n=30)$ & High $(n=22)$ & & \\
\hline \multicolumn{5}{|c|}{ Sensory ( $n=72$ panelists) } \\
\hline Tenderness $^{1}$ & $6.3^{*}$ & 6.7 & 0.2 & 0.11 \\
\hline Juiciness $^{2}$ & 6.6 & 6.9 & 0.2 & 0.09 \\
\hline Flavor $^{3}$ & 7.0 & 7.1 & 0.1 & 0.44 \\
\hline Acceptability $^{4}$ & $6.7^{\mathrm{b}}$ & $7.1^{\mathrm{a}}$ & 0.1 & 0.02 \\
\hline
\end{tabular}

${ }^{1}$ Panelists were asked "How much do you like or dislike the TENDERNESS of the sample?"

${ }^{*}$ Scale for all palatability traits ranged from $1=$ Dislike Extremely to $9=$ Like Extremely.

${ }^{2}$ Panelists were asked "How much do you like or dislike the JUICINESS of the sample?"

${ }^{3}$ Panelists were asked "How much do you like or dislike the FLAVOR of the sample?"

${ }^{4}$ Panelists were asked "How much do you like or dislike the sample OVERALL?"

${ }^{\mathrm{a}, \mathrm{b}}$ Within a row, means without a common superscript differ $(P<0.05)$

IT = Igenity ${ }^{\circledR}$.

Low IT steaks in terms of overall acceptability $(P=$ 0.02). Consumers preferred USDA Prime steaks in terms of acceptability $(P=0.01)$, juiciness $(P<0.01)$, and flavor $(P=0.02)$ to USDA Choice steaks (Table 4$)$, though they did not report a preference in terms of tenderness $(P=0.11)$ between USDA quality grades. 
Table 4. Effects of USDA quality grade on palatability traits assessed by consumer sensory panel

\begin{tabular}{|c|c|c|c|c|}
\hline \multirow[b]{2}{*}{ Trait } & \multicolumn{2}{|c|}{ USDA Quality Grade } & \multirow[b]{2}{*}{ SEM } & \multirow[b]{2}{*}{$P$ valu } \\
\hline & Choice $(n=32)$ & Prime $(n=20)$ & & \\
\hline \multicolumn{5}{|c|}{ Sensory ( $n=72$ panelists) } \\
\hline Tenderness ${ }^{1}$ & $6.3^{*}$ & 6.7 & 0.2 & 0.11 \\
\hline Juiciness $^{2}$ & $6.5^{\mathrm{b}}$ & $7.0^{\mathrm{a}}$ & 0.2 & 0.01 \\
\hline Flavor $^{3}$ & $6.7^{\mathrm{b}}$ & $7.2^{\mathrm{a}}$ & 0.2 & 0.02 \\
\hline Acceptability ${ }^{4}$ & $6.7^{\mathrm{b}}$ & $7.1^{\mathrm{a}}$ & 0.1 & 0.01 \\
\hline
\end{tabular}

${ }^{1}$ Panelists were asked "How much do you like or dislike the TENDERNESS of the sample?"

*Scale for all palatability traits ranged from $1=$ Dislike Extremely to $9=$ Like Extremely,

${ }^{2}$ Panelsits were asked "How much do you like or dislike the JUICINESS of the sample?"

${ }^{3}$ Panelists were asked "How much do you like or dislike the FLAVOR of the sample?"

${ }^{4}$ Panelists were asked "How much do you like or dislike the sample OVERALL?"

${ }^{\mathrm{a}, \mathrm{b}}$ Within a row, means without a common superscript differ $(P<0.05)$. USDA $=$ US Department of Agriculture.

\section{Discussion}

Though these steers were selected for their genetic propensity to be tender and could therefore be expected to all have high IT tenderness indexes, some steers still fell into the Low IT tenderness group (IT index score 3$6 ; n=30$ ). This could be because of estimated heritability for tenderness falling between moderate and high (Shackelford et al., 1994; Mateescu et al., 2015), meaning that the genotype of the dam and sire has a high probability of passing along and therefore influencing the phenotype of their progeny, but passing the desired phenotypic tenderness trait along is not a guarantee. Additionally, tenderness is polygenic, meaning that it is influenced by multiple genes (Page et al., 2002; Goll et al., 2003; Geesink et al., 2006; Kemp et al., 2009). Furthermore, the IT panel does not report genotype as heterozygous or homozygous, it simply assigns an index number for each predicted phenotype (Neogen, Lincoln, NE). Therefore, researchers can speculate about the genes used to evaluate and assign predictions for genetic probability to perform in each category, but the actual single nucleotide polymorphisms used in the panel are proprietary and thus confidential. Aside from the genetic component, tenderness is heavily influenced by environmental factors (Huff and Parrish Jr., 1993; Warner et al., 2010) as well as postmortem events other than proteolysis (Locker and Hagyard, 1963; Yu and Lee, 1986;
Rios-Mera et al., 2017); all the cattle in the present study were harvested at the same location and had come from similar genetic background.

High IT steaks that graded USDA Prime exhibited lower WBSF values, making them more tender than High IT steaks that graded USDA Choice, Low IT steaks that graded USDA Prime, and Low IT steaks that graded USDA Choice. This observation is inconsistent with the findings of Mateescu et al. (2015), who reported a positive genetic correlation between MS and tenderness. Similarly, McBee and Wiles (1967) and Luchak et al. (1998) found a significant decrease in WBSF value as marbling units increased. Magolski et al. (2013) also observed that marbling had more influence on variation in WBSF than other carcass traits measured. This relationship between tenderness and marbling has been documented by Miller (1994), who described increases in reported tenderness of higher-marbled steaks by sensory panelists as the bulk density of each bite was reduced and lubrication was increased. Likewise, Li et al. (2006) observed increased disruption of muscle perimysial structure with increased marbling. The observations of the current study do not show a difference in consumer sensory tenderness, but it would be expected that any improvements in tenderness with increases in marbling are likely because of indirect factors, since no research has shown a direct relationship between tenderness and marbling in beef until the quantity of marbling reached extremely large numbers, such as is observed in Wagyu beef ( $\mathrm{Li}$ et al., 2006). This is further supported by the observation of the present study that MS was not different between High IT and Low IT carcasses. The current study observed this interaction when evaluating steaks from the longissimus lumborum; other muscles of the carcass, however, could respond differently to genetic selection for tenderness.

Consumers preferred USDA Prime striploin steaks over USDA Choice striploin steaks in all categories except tenderness, likely because all of the steaks were very tender. The USDA tenderness program considers anything that is inherently tender-meaning it has not been processed in any way to make it more tenderwith a WBSF value at or below $4.4 \mathrm{~kg}$ to fall within their "Certified Tender" category and anything with a WBSF value at or below $3.9 \mathrm{~kg}$ to fall within their "Certified Very Tender" category (ASTM, 2011). The steers from this experiment that graded USDA Choice had an average WBSF value of $3.31 \mathrm{~kg}$, whereas the USDA Prime steers had an average WBSF value of $3.09 \mathrm{~kg}$. This observation, therefore, is consistent with the findings of Miller et al. (1995), 
who concluded that consumers were unable to detect differences in tenderness when the WBSF values did not exceed $0.5 \mathrm{~kg}$ of difference in tenderness. Furthermore, it has been well documented that increases in marbling lead to improvements in palatability (Jones et al., 1991; Hunt et al., 2014, Corbin et al., 2015). These findings support the observations of this experiment that consumers preferred USDA Prime steaks over USDA Choice steaks in terms of overall acceptability, juiciness, and flavor.

Consumers were not able to detect differences in tenderness between High IT and Low IT steaks, which is likely because WBSF was not different between Low IT and High IT groups. Additionally, the lack of tenderness differences between the IT group in this experiment may also be due to the fact that there was not a gap between the 2 groups. With larger numbers and IT groups with a gap in between (i.e., 1-4 vs. 7-10), consumers may have been able to detect a difference in tenderness. Consumers were also not able to detect differences in juiciness or flavor between IT tenderness groups, which is likely due to the fact that IT tenderness index scores are assigned based on genetics related to postmortem proteolysis specifically (Goll et al., 2003; Geesink et al., 2006; Quaas et al., 2007; Kemp et al., 2009; Warner et al., 2010), which has not been shown to directly impact consumer perception of flavor of beef. Consumer tendency to prefer High IT steaks over Low IT steaks in terms of juiciness can be explained by the work of Huff-Lonergan and Lonergan (2005), who hypothesize that increased proteolysis leads to less myofibril shrinkage, leading to less drip loss, which translates to juicier steaks. It has been observed several times that consumers prefer USDA Prime beef over USDA Choice beef because of the improvements in juiciness, flavor, and overall acceptability (Smith et al., 1987; Corbin et al., 2015; Lucherk et al., 2016). This is consistent with the findings of this experiment, in which consumers preferred the USDA Prime steaks over the USDA Choice steaks in the same categories, likely because of the higher amount of marbling in the USDA Prime steaks than in the USDA Choice steaks.

Currently, there is a USDA premium available for tender carcasses, but it has only been adopted by a few beef processors (ASTM, 2011; Morris, 2017). Given the importance placed on tenderness by consumers in terms of palatability in beef (Koohmaraie et al., 1995; Miller et al., 2001; Koohmaraie and Geesink, 2006), products from animals that have been selected genetically for tenderness may receive a premium in the future. Though there is a tenderness premium available, genetic selection goals still need to be centered around marbling to help producers capture USDA carcass quality premiums, or avoid discounts for carcass quality, which focus primarily on marbling (Smith, 2020).

\section{Conclusions}

Cattle that were selected for tenderness were confirmed to have a tender strip loin even though some carcasses still fell into the Low IT group. Even though all of the cattle were very tender based on WBSF values of the strip loin, cattle that graded USDA Prime were consistently preferred by consumers over USDA Choice cattle in terms of flavor, juiciness, and acceptability regardless of whether they had High IT or Low IT scores. In summary, tenderness is an important part of consumer eating experience and can be capitalized upon via genetic selection. Consumers preferred the steaks that graded USDA Prime because of their acceptability, juiciness, and flavor even though consumers did not report a difference between IT tenderness groups.

Producers who market their breeding animals as having the genetic propensity to produce tender offspring could add value to their animals with a higher chance of being able to gain a premium for their carcass tenderness. With the use of the genetic tools that are available commercially, producers could capitalize on carcass quality traits on which they have not been able to capitalize in the past. This analysis could be made stronger by the provision of dam and sire genetic information as well as evaluation of other muscles. Furthermore, more information is needed about how these tests can be implemented in crossbred cattle that were not selected for tenderness.

\section{Acknowledgments}

The researchers would like to acknowledge Vandal Brand Meats, the University of Idaho Department of Animal and Veterinary Science graduate students, the Washington State University School of Food Science and Dr Carolyn Ross's laboratory, and the Animal and Veterinary Science Meat Science Laboratory undergraduate employees for their assistance with this project. Kings River Ranch supplied the product for analysis. Support for this research project was also provided by the Idaho Agricultural Experiment Station. 


\section{Literature Cited}

ASTM. 2011. F2925-11. Standard specification for tenderness marketing claims associated with meat cuts derived from beef. ASTM International, West Conshohocken, PA. https://doi. org/10.1520/F2925-11.

Corbin, C. H., T. G. O’Quinn, A. J. Garmyn, J. F. Legako, M. R. Hunt, T. T. N. Dinh, R. J. Rathmann, J. C. Brooks, and M. F. Miller. 2015. Sensory evaluation of tender beef strip loin steaks of varying marbling levels and quality treatments. Meat Sci. 100:24-31. https://doi.org/10.1016/j.meatsci. 2014.09.009.

Geesink, G. H., S. Kuchay, A. H. Chishti, and M. Koohmaraie. 2006. Micro-calpain is essential for postmortem proteolysis of muscle proteins. J. Anim. Sci. 84:2834-2840. https://doi. org/10.2527/jas.2006-122.

Goll, D. E., V. F. Thompson, H. Li, W. Wei, and J. Cong. 2003. The calpain system. Physiol. Rev. 83:731-801. https://doi.org/10. 1152/physrev.00029.2002.

Hedrick, H. 1983. Methods of estimating live animal and carcass composition. J. Anim. Sci. 57:1316-1327. https://doi.org/ 10.2527/jas1983.5751316x.

Hocquette, J. F., S. Lehnert, W. Barendse, I. Cassar-Malek, and B. Picard. 2007. Recent advances in cattle functional genomics and their application to beef quality. Animal. 1:159-173. https://doi.org/10.1017/S1751731107658042.

Hope-Jones, M., and P. E. Strydom. 2010. The efficiency of electrical stimulation to counteract the negative effects of b-agonists on meat tenderness of feedlot cattle. Meat Sci. 86:699705. https://doi.org/10.1016/j.meatsci.2010.06.008.

Huff, E. J., and F. C. Parrish, Jr. 1993. Bovine longissimus muscle tenderness as affected by postmortem aging time, animal age and sex. J. Food Sci. 58:713-716. https://doi.org/10.1111/j. 1365-2621.1993.tb09341.x.

Huff-Lonergan, E., and S. M. Lonergan. 2005. Mechanisms of water-holding capacity of meat: The role of postmortem biochemical and structural changes. Meat Sci. 71:194-204. https://doi.org/10.1016/j.meatsci.2005.04.022.

Hunt, M. R., A. J. Garmyn, T. G. O’Quinn, C. H. Corbin, J. F. Legako, R. J. Rathmann, J. C. Brooks, and M. F. Miller. 2014. Consumer assessment of beef palatability from four beef muscles from USDA Choice and Select graded carcasses. Meat Sci. 98:1-8. https://doi.org/10.1016/j.meatsci.2014.04. 004.

Jones, S. D. M., L. E. Jeremiah, A. K. W. Tong, S. Lutz, and W. M. Robertson. 1991. The effects of marbling level, electrical stimulation, and post-mortem aging on the cooking and palatability properties of beef rib-eye steaks. Can. J. Anim. Sci. 71:1037-1043. https://doi.org/10.4141/cjas91-125.

Kemp, C. M., P. L. Sensky, R. G. Bardsley, P. J. Buttery, and T. Parr. 2009. Tenderness- An enzymatic view. Meat Sci. 84:248-256. https://doi.org/10.1016/j.meatsci.2009.06.008.

Koohmaraie, M. 1992. The role of $\mathrm{Ca}++$ dependent proteases (calpains) in post mortem proteolysis and meat tenderness. Biochimie. 74:239-245. https://doi.org/10.1016/0300-9084 (92)90122-u.

Koohmaraie, M. 1994. Muscle proteinases and meat aging. Meat Sci. 36:93-104. https://doi.org/10.1016/0309-1740(94)90036-1.
Koohmaraie, M., and G. H. Geesink. 2006. Contribution of postmortem biochemistry to the delivery of consistent meat quality with particular focus on the calpain system. Meat Sci. 74:34-43. https://doi.org/10.1016/j.meatsi.2006.04.025.

Koohmaraie, M., T. L. Wheeler, and S. D. Shackelford. 1995. Beef tenderness: Regulation and prediction. USDA-ARS U.S. Meat Animal Research Center, Clay Center, NE.

Li, C., G. Zhou, X. Xu, J. Zhang, S. Xu, and Y. Ji. 2006. Effects of marbling on meat quality characteristics and intramuscular connective tissue of beef longissumus muscle. Asian Austral. J. Anim. 19:1799-1808. https://doi.org/10.5713/ ajas.2006.1799.

Locker, R. H., and C. J. Hagyard. 1963. A cold shortening effect in beef muscles. J. Sci. Food Agr. 14:787-793. https://doi.org/ 10.1002/jsfa.2740141103.

Luchak, G. L., R. K. Miller, K. E. Belk, D. S. Hale, S. A. Michaelsen, D. D. Johnson, R. L. West, F. W. Leak, H. R. Cross, and J. W. Savell. 1998. Determination of sensory, chemical and cooking characteristics of retail beef cuts differing in intramuscular and external fat. Meat Sci. 50:55-72. https://doi.org/10.1016/S0309-1740(98)00016-3.

Lucherk, L. W., T. G. O’Quinn, J. F. Legako, R. J. Rathmann, J. C. Brooks, and M. F. Miller. 2016. Consumer and trained panel evaluation of beef strip steaks of varying marbling and enhancement levels cooked to three degrees of doneness. Meat Sci. 122:145-154. https://doi.org/10.1016/j.meatsci. 2016.08.005.

Magolski, J. D., D. S. Buchanan, K. R. Maddock-Carlin, V. L. Anderson, D. J. Newman, and E. P. Berg. 2013. Relationship between commercially available DNA analysis and phenotypic observations on beef quality and tenderness. Meat Sci. 95:480-485. https://doi.org/10.1016/j.meatsci. 2013.05.024.

Mateescu, R. G., D. J. Garrick, A. J. Garmyn, D. L. VanOverbeke, G. G. Mafi, and J. M. Reecy. 2015. Genetic parameters for sensory traits in longissimus muscle and their associations with tenderness, marbling score, and intramuscular fat in Angus cattle. J. Anim. Sci. 93:21-27. https://doi.org/10. 2527/jas.2014-8405.

McBee, J. L., and J. A. Wiles. 1967. Influence of marbling and carcass grade on the physical and chemical characteristics of beef. J. Anim. Sci. 26:701-704. https://doi.org/10.2527/ jas1967.264701x.

McEvers, T. J., W. T. Nichols, J. P. Hutcheson, M. D. Edmonds, and T. E. Lawrence. 2012. Feeding performance, carcass characteristics, and tenderness attributes of steers sorted by the Igenity tenderness panel and fed zilpaterol hydrochloride. J. Anim. Sci. 90:4140-4147. https://doi.org/10.2527/jas20125120.

Miller, R. K. 1994. Quality characteristics. In: D. M. Kinsman, A. W. Kotula, B. C. Breidenstein, editors, Muscle foods: Meat, poultry, and seafood technology, Springer, Boston, MA. p. 296-332.

Miller, M. F., M. A. Carr, C. B. Ramsey, K. L. Crockett, and L. C. Hoover. 2001. Consumer thresholds for establishing the value of beef tenderness. J. Anim. Sci. 79:3062-3068. https://doi. org/10.2527/2001.79123062x.

Miller, M. F., L. C. Hoover, A. L. Cook, A. A. Guerra, and K. L. Huffman. 1995. Consumer acceptability of beef steak 
tenderness in home and restaurant. J. Food Sci. 60:963-965. https://doi.org/10.1111/j.1365-2621.1995.tb06271.

Morris, C. 2017. "USDA Tender" - A cooperative effort with the U.S. beef industry. U.S. Department of Agriculture. February 21, 2017. https://www.usda.gov/media/blog/2013/08/12/usdatender-cooperative-effort-us-beef-industry. (Accessed 16 January 2020).

Page, B. T., E. Casas, M. P. Heaton, N. G. Cullen, D. L. Hyndman, C. A. Morris, A. M. Crawford, T. L. Wheeler, M. Koohmaraie, J. W. Keele, and T. P. L. Smith. 2002. Evaluation of single-nucleotide polymorphisms in CAPN1 for association with meat tenderness in cattle. J. Anim. Sci. 80:3077-3085. https://doi.org/10.2527/2002.80123077x.

Picard, B., M. Gagaoua, D. Micol., I. Cassar-Malek, J. F. Hocquette, and C. E. M. Terlouw. 2014. Inverse relationships between biomarkers and beef tenderness according to contractile and metabolic properties of the muscle. J Agr. Food Chem. 62:9808-9818. https://doi.org/10.1021/ jf501528s.

Picard, B., B. Lebret, I. Cassar-Malek, L. Liaubet, C. Berri, E. Le Bihan-Duval, J. F. Hocquette, and G. Renand. 2015. Recent advances in omic technologies for meat quality management. Meat Sci. 109:18-26. https://doi.org/10.1016/j.meatsci.2015. 05.003

Pollak, E. J., G. L. Bennett, W. M. Snelling, R. M. Thallman, and L. A. Kuehn. 2012. Genomics and the global beef cattle industry. Anim. Prod. Sci. 52:92-99. https://doi.org/10.1071/ AN11120.

Quaas, R. L., J. Li, R. M. Thallman, A. L. Van Eenennaam, R. L. Fernando, and C. Gill. 2007. Validation of commercial DNA tests for quantitative beef quality traits. J. Anim. Sci. 85:891900. https://doi.org/10.2527/jas.2006-512.

Rios-Mera, J. D., J. S. S. Pinto, and C. J. Contreras-Castillo. 2017. Effect of ultimate $\mathrm{pH}$ and ageing on thermal denaturation of bovine muscle protein. Meat Sci. 131:25-27. https://doi. org/10.1016/j.meatsci.2017.04.017.

Schroeder, T. C., G. T. Tonsor, and J. Mintert. 2013. Beef demand: Recent determinants and future drivers. Research project completed for the Cattlemen's Beef Board. Kansas State University. August 22, 2013. https://www.agmanager.info/livestock-meat/ meat-demand/beef-demand-recent-determinants-and-futuredrivers. (Accessed 16 December 2019).

Shackelford, S. D., M. Koohmaraie, L. V. Cundiff, K. E. Gregory, G. A. Rohrer, and J. W. Savell. 1994. Heritabilities and phenotypic and genetic correlations for bovine postrigor calpastatin activity, intramuscular fat content, Warner-Bratzler shear force, retail product yield, and growth rate. J. Anim. Sci. 72:857-863. https://doi.org/10.2527/1994.724857x.

Smith, B. 2020. USDA beef carcass price equivalent index value. USDA Market News. https://www.ams.usda.gov/mnreports/ nw_ls410.txt. (Accessed April 8, 2020).

Smith, G. C., J. W. Savell, H. R. Cross, Z. L. Carpenter, C. E. Murphey, G. W. Davie, H. C. Abraham, F. C. Parrish, Jr., and B. W. Berry. 1987. Relationship of USDA quality grades to palatability of cooked beef. J. Food Quality. 10:269-286. https://doi.org/10.1111/j.1745-4557.1987.tb00819.x.

Van Eenennaam, A. L. 2016. Use of genetic marker information in beef cattle selection. Paper presented at: 2016 Applied Reproductive Strategies in Beef Cattle, Des Moines, IA, September 7-8, 2016. p. 234-241.

Warner, R. D., P. L. Greenwood, D. W. Pethick, and D. M. Ferguson. 2010. Genetic and environmental effects on meat quality. Meat Sci. 86:171-183. https://doi.org/10.1016/j. meatsci.2010.04.042.

Yu, L. P., and Y. B. Lee. 1986. Effects of postmortem $\mathrm{pH}$ and temperature muscle structure and meat tenderness. J. Food Sci. 51:774-780. https://doi.org/10.1111/j.1365-2621. 1986.tb13931.x. 